\title{
TO THE READER
}

In our effort to achieve a satisfactory middle ground between a technical and detailed guidebook to Nemea for scholars and a more general guide for other visitors, we offer definitions of technical terms at their first appearance in the text. With the aid of the index, these definitions can easily be found again.

Notations consisting of a letter or letters followed by a set of numbers refer to the permanent inventory system by which each artifact is uniquely identified in the Nemea system. BR 671 , for example, is the 671st artifact inventoried in the BR[onze] category; A 100 is the 100th artifact inventoried in the $A[r$ rchitecture] category; ss 8 is the 8 th artifact in the s[tone] s[culpture] category, and so forth.

We hope that you may read this guide at Nemea, beginning perhaps at the marble picnic tables at the entrance to the site or on the benches on the porch of the museum. We wish you a happy visit to Nemea! 
